\title{
Quadruplex PCR assay for identification of Corynebacterium pseudotuberculosis differentiating biovar Ovis and Equi
}

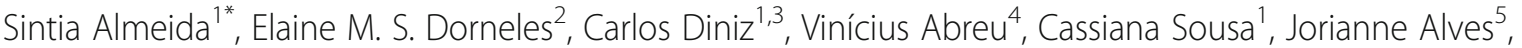
Adriana Carneiro ${ }^{5}$, Priscilla Bagano ${ }^{1}$, Sharon Spier ${ }^{6}$, Debmalya Barh ${ }^{1,7}$, Andrey P. Lage $^{2}$, Henrique Figueiredo $^{8}$ and Vasco Azevedo ${ }^{1 *}$

\begin{abstract}
Background: Corynebacterium pseudotuberculosis is classified into two biovars, nitrate-negative biovar Ovis which is the etiologic agent of caseous lymphadenitis in small ruminants and nitrate-positive biovar Equi, which causes abscesses and ulcerative lymphangitis in equines. The aim of this study was to develop a quadruplex PCR assay that would allow simultaneous detection and biovar-typing of C. pseudotuberculosis.

Methods: In the present study, genomes of C. pseudotuberculosis strains were used to identify the genes involved in the nitrate reduction pathway to improve a species identification three-primer multiplex PCR assay. The nitrate reductase gene (narG) was included in the PCR assay along with the $165, r p o B$ and pld genes to enhance the diagnosis of the multiplex PCR at biovar level.

Results: A novel quadruplex PCR assay for C. pseudotuberculosis species and biovar identification was developed. The results of the quadruplex PCR of 348 strains, 346 previously well-characterized clinical isolates of $C$. pseudotuberculosis from different hosts (goats, sheep, horse, cattle, buffalo, llamas and humans), the vaccine strain 1002 and the type strain ATCC $19410^{\top}$, were compared to the results of nitrate reductase identification by biochemical test. The McNemar's Chi-squared test used to compare the two methods used for C. pseudotuberculosis biovar identification showed no significant difference $(P=0.75)[95 \% \mathrm{Cl}$ for odds ratio $(0.16-6.14)]$ between the quadruplex PCR and the nitrate biochemical test. Concordant results were observed for $97.13 \%$ (338 / 348) of the tested strains and the kappa value was 0.94 [95\% Cl (0.90-0.98)].
\end{abstract}

Conclusions: The ability of the quadruplex assay to discriminate between C. pseudotuberculosis biovar Ovis and Equi strains enhances its usefulness in the clinical microbiology laboratory.

Keywords: Caseous lymphadenitis, Diagnosis, Nitrate reductase, Horse, Sheep, Goats

\section{Background}

Corynebacterium pseudotuberculosis is a facultative intracellular bacterium that is the causative agent of caseous lymphadenitis (CLA) in goats and sheep, abscesses and ulcerative lymphangitis in horses and oedematous skin disease (OSD) in Buffalo. It also causes sporadic infections in other species including cattle, camels, llamas, and humans [1-4]. C. pseudotuberculosis can be classified in

\footnotetext{
*Correspondence: sintiaalmeida@gmail.com; vasco@icb.ufmg.br ${ }^{1}$ Instituto de Ciências Biológicas, Federal University of Minas Gerais, Belo Horizonte, MG, Brazil

Full list of author information is available at the end of the article
}

two biovars, based on their ability to convert nitrate to nitrite, nitrate-positive strains are classified as biovar Equi and the nitrate negative ones as biovar Ovis [5]. In sheep and goats, CLA is predominantly caused by biovar Ovis strains, whereas horses and buffalos are mostly infected by biovar Equi strains [6-8]. Infection by C. pseudotuberculosis is distributed worldwide, causing significant disease in horse, sheep and goat herds $[8,9]$. The main economic losses attributed to C. pseudotuberculosis infection include decreased milk production, decreased weight gain, reduced value of hides due to scarring, and the cost of the drugs and labor needed to treat disease [9]. 
Direct and indirect tests to detect C. pseudotuberculosis have already been proposed, such as complement fixation test [10], synergistic hemolysis inhibition test [11], microagglutination assay [12], phospholipase D (PLD) antigen-based ELISA [13] and a multiplex PCR developed by our research group [14]. While these tests are useful for clinical diagnosis in diseased animals, none can differentiate the two biovars of C. pseudotuberculosis, which is currently only accomplished by biochemical tests. Differences between biovars are relevant for host and tissue specificity and appear to be associated with virulence $[15,16]$.

Disease caused by $C$. pseudotuberculosis biovars has different clinical manifestations in the susceptible hosts $[6,8,17,18]$, and biovar identification is important for understanding the epidemiology of infection, and consequently for disease control. Moreover, biovar identification can also have clinical implications. Since cattle can be infected by strains of both biovars, which may have different tissue preferences: biovar Ovis infects chiefly the mammary gland [17] and skin [18] and biovar Equi causes ulcerative lymphangitis and coronet lesions $[9,19,20]$.

A dominant genetic characteristic that differentiates the biovars of $C$. pseudotuberculosis is the presence of the nitrate reduction operon in the biovar Equi strains [21]. Additionally, biovar Equi strains have 15 genes that are absent in biovar Ovis strains, including the narKGHJI operon, and a gene cluster encoding the molybdopterins moeB, moaE, $\operatorname{molB}$, $\operatorname{mol} A$, moe $Y$, moaC, moeA, and moaA and two hypothetical proteins [21].

Currently, only nitrate reduction test distinguishes C. pseudotuberculosis biovars Ovis and Equi [5, 9]. The available phenotypic tests, performed in a laboratory or commercially available, for C. pseudotuberculosis identification are usually effective. However, the phenotypic tests can be expensive and unavailable for some laboratories that prefer to use molecular techniques. Currently, clinical microbiology laboratories are experiencing a change from classical to new diagnostic tools as PCR, real-time PCR, sequencing and MALDI-TOF mass spectrometry [22, 23], which, due to the decrease in costs, may prefer to use molecular over biochemical tests. Moreover, the molecular tests are usually faster, easier and have less subjectivity in interpretation [24].

Our collaborative group has sequenced more than 60 C. pseudotuberculosis strains isolated from different hosts around the world, performing genomic, proteomic and clinical studies to not only to understand the pathogen but also try to find a way to control the spread of bacteria. Thus, the aim of this study was to develop a quadruplex PCR assay that would allow simultaneous detection and biovar-typing of C. pseudotuberculosis strains.

\section{Methods \\ Nitrate reductase genes}

Presence or absence of nitrate reductase genes were analyzed in nineteen $C$. pseudotuberculosis genomes (Table 1) in our previous work [21].

\section{Bacterial strains and culture conditions}

A total of 348 C. pseudotuberculosis strains, 346 field isolates [25-27], C. pseudotuberculosis ATCC 19410 type strain, and C. pseudotuberculosis 1002 vaccine strain, were used in this study. These strains were obtained from the repository of the Laboratório de Genética Celular e Molecular, Instituto de Ciências Biológicas and of the Laboratório de Bacteriologia Aplicada, Escola de Veterinária of the Universidade Federal de Minas Gerais. C. pseudotuberculosis biovars Ovis and Equi were aerobically grown in brain heart infusion (BHI) (Acumedia Manufacturers, Baltimore, USA) agar plates at $37{ }^{\circ} \mathrm{C}$ for $48 \mathrm{~h}$. The C. pseudotuberculosis isolates were identified by standard biochemical tests $[9,28,29]$. Nitrate reduction was assessed using nitrate broth (Merck, Billerica, USA) and further reduction beyond nitrite was tested by addition of zinc dust (Sigma-Aldrich, St Louis, USA) [28].

\section{Genomic DNA extraction, primers, and quadruplex PCR}

Genomic DNA extraction were performed according to the previously described protocol [30]. The oligonucleotide primers used in this study are listed in Table 2. Primers used to target $16 S$ rRNA, rpoB, and pld genes of $C$. pseudotuberculosis were previously described [14, 31, 32]. Primers targeting the narG gene were designed by aligning the narG nucleotide sequences of $C$. pseudotuberculosis biovar Equi strains available from the whole genome sequenced strains (Table 1). Quadruplex PCR were carried out in a final volume of $50 \mu \mathrm{L}$, containing $20 \mathrm{ng}$ of genomic DNA, $1 \mu \mathrm{M}$ of each primer, $0.25 \mathrm{mM}$ dNTPs, 1 units of Taq DNA polymerase (Life Technologies, Carlsbad, USA), $2 \mathrm{mM} \mathrm{MgCl}_{2}$, and $1 \mathrm{X}$ buffer (200 mM Tris- $\mathrm{HCl} \mathrm{pH} 8.4,500 \mathrm{mM} \mathrm{KCl)} \mathrm{(Life} \mathrm{Tech-}$ nologies, Carlsbad, USA). Amplification was performed using the thermal cycler (PTC-100, MJ Research, Hercules, USA) as follows: the first denaturation at $95{ }^{\circ} \mathrm{C}$ for $4 \mathrm{~min}$; followed by 30 cycles of denaturation at $95{ }^{\circ} \mathrm{C}$ for $30 \mathrm{~s}$, annealing at $58{ }^{\circ} \mathrm{C}$ for the $30 \mathrm{~s}$, and extension at $72{ }^{\circ} \mathrm{C}$ for $1.5 \mathrm{~min}$. The amplified products were submitted to electrophoresis in $1.0 \%$ agarose gel $(w / v)$ in Tris-borate-EDTA (TBE) buffer (89 mM Tris Base, $89 \mathrm{mM}$ Boric Acid and $2 \mathrm{mM}$ EDTA pH 8.0), stained with $0.5 \mathrm{mg} / \mathrm{mL}$ ethidium bromide and visualized under UV light. 
Table 1 Corynebacterium pseudotuberculosis strains with the whole genome sequenced available in the NCBI GenBank (www.ncbi.nlm.nih.gov/genbank) in 2015

\begin{tabular}{|c|c|c|c|c|c|c|c|}
\hline Strain & Biovar & Host & Country & Genome size (MB) & Sequencing status & NCBI access & Reference \\
\hline 1002 & Ovis & Goat & Brazil, & 2.33511 & Complete & NC_017300.1 & (37) \\
\hline $\mathrm{C} 231$ & Ovis & Sheep & Australia & 2.32821 & Complete & NC_017301.1 & (37) \\
\hline FRC41 & Ovis & Human & France & 2.33791 & Complete & NC_014329.1 & (38) \\
\hline 119 & Ovis & Cow & Israel & 2.33773 & Complete & NC_017303.1 & (39) \\
\hline PAT10 & Ovis & Sheep & Argentine & 2.33532 & Complete & NC_017305.1 & (40) \\
\hline $42 / 02-A$ & Ovis & Sheep & Australia & 2.33761 & Complete & NC_017306.1 & (41) \\
\hline $3 / 99-5$ & Ovis & Sheep & Scotland & 2.33794 & Complete & NC_016781.1 & (41) \\
\hline 267 & Ovis & Llama & USA & 2.33763 & Complete & NC_017462.1 & (6) \\
\hline P54B96 & Ovis & Antelope & South Africa & 2.33794 & Complete & NC_017031.1 & $(42)$ \\
\hline CIP5297 & Equi & Horse & Kenya & 2.32059 & Complete & NC_017307.1 & (43) \\
\hline $1 / 06-A$ & Equi & Horse & USA & 2.27912 & Complete & NC_017308.1 & (44) \\
\hline 316 & Equi & Horse & USA & 2.31041 & Complete & NC_016932.1 & (45) \\
\hline 258 & Equi & Horse & Belgium & 2.36982 & Complete & NC_017945.1 & (46) \\
\hline 162 & Equi & Camel & UK & 2.29346 & Complete & NC_018019.1 & (42) \\
\hline 31 & Equi & Buffalo & Egypt & 2.38969 & Complete & NC_017730.1 & (47) \\
\hline 262 & Equi & Cattle & Belgium & 2.32575 & Complete & NZ_CP012022.1 & - \\
\hline MB20 & Equi & Horse & USA & 2.36309 & Draft & JPUV01 & (48) \\
\hline E19 & Equi & Horse & Unknow & 2.36796 & Complete & NZ_CP012136.1 & - \\
\hline CCUG27541 & Equi & Horse & Unknow & 2.37942 & Draft & JPJB01 & (49) \\
\hline
\end{tabular}

Table 2 List of oligonucleotide primers used in this study

\begin{tabular}{|c|c|c|c|c|c|}
\hline Target gene & Primers & Sequence $\left(5^{\prime} \rightarrow 3^{\prime}\right)$ & Amplicom size (bp) & Multiplex PCR assay & Reference \\
\hline \multirow[t]{2}{*}{$16 S$ rRNA ${ }^{a}$} & Forward & ACCGCACTTTAGTGTGTGTG & 816 & Yes & $(25)$ \\
\hline & Reverse & TCTCTACGCCGATCTTGTAT & & & \\
\hline \multirow[t]{2}{*}{$r p o B^{a}$} & Forward & CGTATGAACATCGGCCAGGT & 446 & Yes & (26) \\
\hline & Reverse & TCCATTTCGCCGAAGCGCTG & & & \\
\hline \multirow[t]{2}{*}{ pld $d^{a}$} & Forward & ATAAGCGTAAGCAGGGAGCA & 203 & Yes & $(14)$ \\
\hline & Reverse & ATCAGCGGTGATTGTCTTCCAGG & & & \\
\hline \multirow[t]{2}{*}{$n a r G^{a}$} & Forward & ACCCGTACTTGCACTCTITC & 612 & Yes & Present Study \\
\hline & Reverse & AGTCAGTACTTCCGCAGGTC & & & \\
\hline \multirow[t]{2}{*}{ nart } & Forward & GCTGAAGCAAGTTCGTGTCT & 202 & No & Present Study \\
\hline & Reverse & GTAACGGTCAGAGAACCATCC & & & \\
\hline \multirow[t]{2}{*}{ nark } & Forward & GCTGAAGCAAGTTCGTGTCT & 202 & No & Present Study \\
\hline & Reverse & GTAACGGTCAGAGAACCATCC & & & \\
\hline \multirow[t]{2}{*}{ narG2 } & Forward & CAACGTGGTACCTGGTATCTG & 200 & No & Present Study \\
\hline & Reverse & CATAGGGAGAGCGAGAACAA & & & \\
\hline \multirow[t]{2}{*}{ narH } & Forward & GATTCTACTGACCGCCATCTC & 196 & No & Present Study \\
\hline & Reverse & ATCAGTACCTGTCATGCCTACC & & & \\
\hline \multirow[t]{2}{*}{ nar」 } & Forward & CGTGATGGTATAGAGGTGCTG & 198 & No & Present Study \\
\hline & Reverse & GTTGGAAGCAGTAGGGAAGGGAG & & & \\
\hline \multirow[t]{2}{*}{ narl } & Forward & CTGTATCCACACAGGTGTTCG & 215 & No & Present Study \\
\hline & Reverse & GTATCCTACAGGCGCTGAGA & & & \\
\hline
\end{tabular}




\section{Sequencing of singleplex PCR products}

In order to confirm the quadruplex PCR results, ten randomly chosen isolates were tested further in singleplex PCR assays with the four C. pseudotuberculosis-specific primer pairs. PCR products were purified using Agencourt AMPure XP (Beckman Coulter Company, Beverly, Massachusetts, USA) according to the manufacturer's instructions, and each product was sequenced in both directions using primers targeting the $16 \mathrm{~S}$ rRNA, rpoB, pld and narG gene and the Big Dye V3.1 Terminator Kit (Applied Biosystems, USA) using an ABI 3500 DNA analyzer (Applied Biosystems, California, USA). Sequences were analyzed on the Geneious suite of molecular biology (http://www.geneious.com) with 16S rRNA (GenBank accession nos X81916, X81907, and X84255), rpoB (GenBank accession no. AY492239), pld (GenBank accession nos L16586 and L16587) and narG (GenBank accession no AJF93840.1) as the reference genes.

\section{Statistical analysis}

Comparison between nitrate reduction test and quadruplex PCR was performed by McNemar's Chi-squared test, and the agreement was calculated using the kappa statistic. Statistical analysis were performed using the packages psych [33] and epibasix [34] on R software version 3.2.3 [35].

\section{Results}

Comparative genome analysis showed that C. pseudotuberculosis biovar Equi strains (258, 31, 262, MB20, E19 and CCUG27541) had narKGHJI gene clusters, however strains 1/06-A, 316, 162, and CIP52.97, although showing positive results in the nitrate reduction test, did not exhibit narKGHJI operon in their genome. On the other hand, genomic sequence analysis identified partial genes molB, narJ, moeA, and moeB in the strains 1/06-A, 162 and CIP52.97.

Since the strains 1/06-A, 316, 162, and CIP52.97 were nitrate reductase positive in biochemical test and the genes were not identified in their genomes, primers to target narKGHJI cluster and narT gene were designed (Table 2). The PCR tests (Additional file 1: Figure S1), sequencing and the optical map showed that the genes for narKGHJI and narT are present in the genomes of those strains (data not shown).

The multiplex PCR assay that targets $16 S$ rRNA, rpoB and pld genes [14] was improved by the inclusion of $C$. pseudotuberculosis biovar-specific primers for the narG gene (narG - Table 2), in a novel quadruplex PCR assay (Fig. 1). The assessment of our quadruplex PCR assay was performed in a double-blind fashion. The results of the quadruplex PCR of the 348 previously well-characterized strains of $C$. pseudotuberculosis from different hosts (goats, sheep, horse, cattle, buffalo, llamas

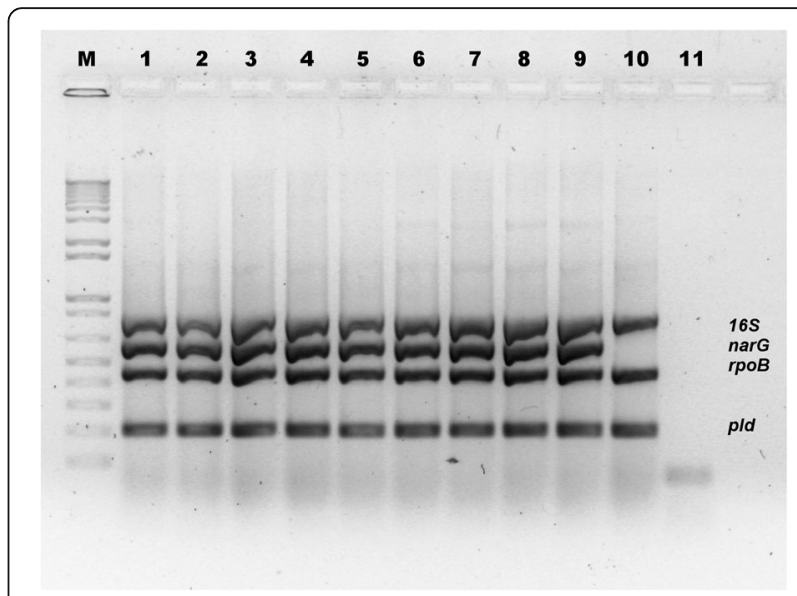

Fig. 1 Four-primer quadruplex PCR for C. pseudotuberculosis species and biovar identification.Agarose gel 1.5\% showing the PCR amplification of quadruplex PCR assay stained with ethidium bromide $(0.5 \mathrm{mg} / \mathrm{mL}$ ).L: GeneRuler DNA Ladder (Fermentas, Vilnius, Lithuania); Lanes 1-9:C. pseudotuberculosis biovar Equi strains C31, 258, 262, 162, 5297, 1/06A, EG-37, EG-42 and I-37; Lane 10:C. pseudotuberculosis biovar Ovis strain 1002

and humans) [21, 25-27] were compared to the results of nitrate reductase identification by biochemical test, and are shown in Table 3. The McNemar's Chi-squared test used to compare the two methods employed for $C$. pseudotuberculosis biovar identification showed no significant difference $(P=0.75)$, with an odds ratio of 1 (95\% CI for the odds ratio: 0.16-6.14) between the quadruplex PCR and the nitrate biochemical test. Concordant results were observed for $97.13 \%$ (338/348) of the strains (Table 3), and the kappa statistic value was 0.94 [95\% CI (0.90-0.98)], denoting excellent concordance between biochemical and molecular tests for nitrate reductase identification. The limit of detection of the new quadruplex PCR was $200 \mathrm{ng}$ of DNA from C. pseudotuberculosis biovar Equi, which corresponds to approximately 100 bacteria.

\section{Discussion}

Previously, identification of C. pseudotuberculosis biovars was only possible only through the established procedures that included isolation and identification of the agent using biochemical tests such as the nitrate reduction test, which separates the nitrate-positive biovar Equi from nitrate negative biovar Ovis strains [5]. Herein, we developed, by the addition of a new oligonucleotide primer pair targeting the narG gene to the former multiplex PCR assay [14], a robust new assay for identification of C. pseudotuberculosis at species and biovar levels.

The comparative genome analysis showed in C. pseudotuberculosis biovar Equi strains (258, 31, 262, MB20, E19 and CCUG27541) narKGHJI gene clusters that participate via the respiratory anaerobic process of the 
Table 3 Comparison of biochemical test and a multiplex PCR assay employed for Corynebacterium pseudotuberculosis biovar identification

\begin{tabular}{llll}
\hline Multiplex & Biochemical test & & TOTAL \\
\cline { 2 - 3 } PCR assay & Nitrate positive & Nitrate negative & \\
\hline Nitrate positive & 133 & 5 & 138 \\
Nitrate negative & 5 & 205 & 210 \\
$\quad$ Total & 138 & 210 & 348 \\
\hline
\end{tabular}

McNemar's Chi-squared test $=\mathrm{P}=0.75$, Odds Ratio: $1(95 \% \mathrm{Cl}$ for the odds ratio: $0.16-6.14)$

Kappa coefficient $=0.94(95 \% \mathrm{Cl}: 0.91-0.98)$

nitrate reduction similar to Escherichia coli [21,36]. The C. pseudotuberculosis narKGHJI gene cluster showed significant similarity with the protein sequences found in other Actinomycetes, such as C. diphtheriae, C. glutamicum, and Mycobacterium tuberculosis. All C. pseudotuberculosis biovar Ovis strains do not present any gene of the narKGHJI operon in their genomes [21].

The nitrate locus in C. pseudotuberculosis is composed of the narKGHJI operon and by a cluster of genes encoding the molybdopterin moeB, moaE, molB, molA, moeY, moaC, moeA, and moaA (Fig. 2) [21]. Molybdopterin is a cofactor that is indispensable for the activity of nitrate reductase. In the narGHI complex, the narG gene is a member of a superfamily of enzymes that use a Molybdopterin-guanine-dinucleotide (Mo-bisMGD) cofactor (bisMGD) for their catalytic activity.

Our results showed that among the 348 C. pseudotuberculosis tested, only 10 strains $(2.87 \%)$ showed differences between the biovar classification provided by molecular and biochemical tests (Table 3), which was observed even after repeating the assays. Furthermore, the kappa coefficient, which is a robust statistic that measures interrater agreement for qualitative items, confirms that regardless of the technique used for biovar classification the results obtained were very similar. It is also important to consider that kappa values range from -1 to +1 , where 1 represents a perfect agreement between the raters, and 0.81 to 1.00 represents almost perfect agreement, such as the observed in our data $(0.94)[28,37]$. Discordance between both phenotypic and genotypic methods can be explained by the effect of environmental factors on gene expression [29, 38] amino-acid substitution, the genetic background of the strain (that can vary according to geographical locations) and mutations. Considering discordances due to mutations genotypic tests have proven to be more reliable and sensitive as diagnostic tool than phenotypic tests [30-32, 39-42]. Others studies also showed discordant results between genotypic versus phenotypic methods [30-32, 39-41, 43, 44].

To our acknowledgement, this is the first molecular approach able to clearly differentiate between C. pseudotuberculosis biovar Ovis and Equi, although different restriction patterns, ribotypes and ERIC-PCR clustering pattern have been associated to biovars [26, 36, 45-47]. The advantages of multiplex PCR assay over biochemical tests are the speed, performance and reproducibility, and the ability to test large numbers of isolates simultaneously $[26,45,46]$. Identification is based upon the number and sizes of four products amplified by PCR. Moreover, the use of molecular techniques reduces the manipulation of viable bacteria in the laboratory and consequently the risk of accidental infection, as C. pseudotuberculosis can eventually be a zoonotic agent [2]. Moreover, this new diagnostic tool, the quadruplex PCR assay for identification and

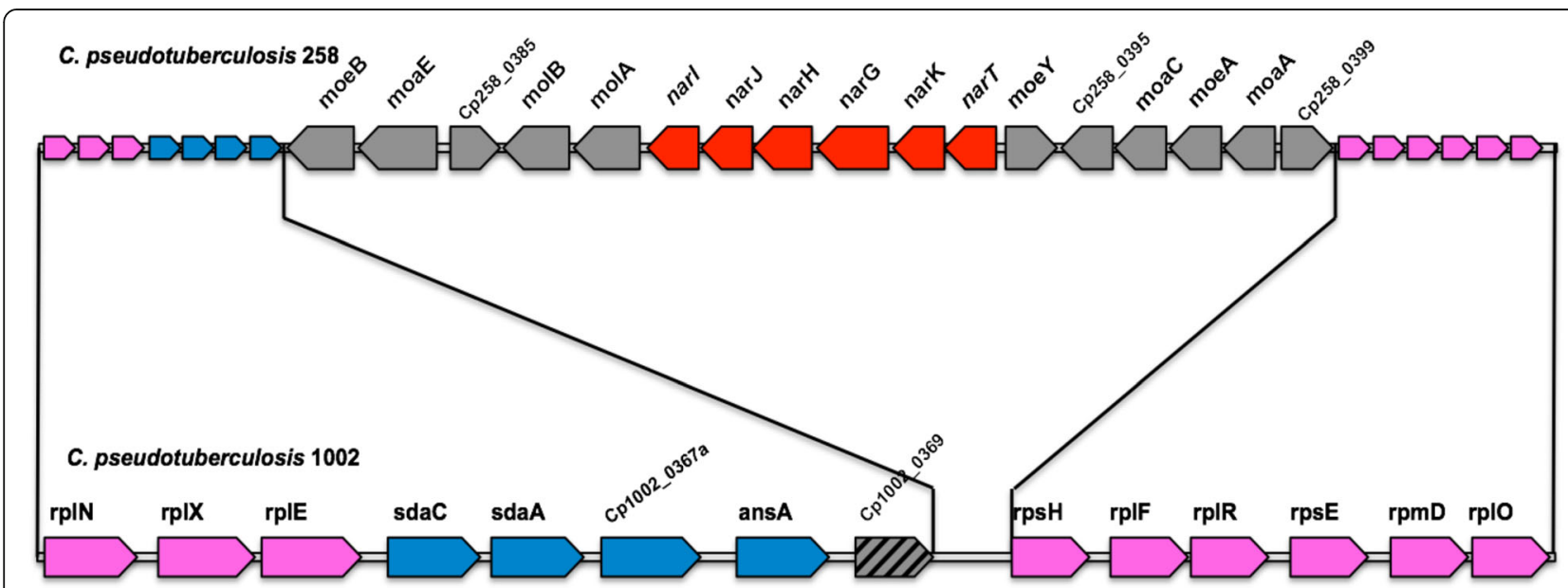

Fig. 2 Nitrate locus from C. pseudotuberculosis biovar Equi.This locus contains: the genes encoding the molybdopterin moeB, moaE, molB, molA, moeY, moaC, moeA and moaA and the genes encoding the nitrate reductase nark, narG, narH, narJ, narl. Insertion show between ans $\mathrm{A}$ and $r p s \mathrm{H}$ genes is lacking in nitrate negative C. pseudotuberculosis biovar Ovis strains. Arrows represent open reading frames and their orientations. Blue and pink: common genes shared between C. pseudotuberculosis biovar Ovis and biovar Equi strains. Pink: ribosomal proteins. Hatched: additional or different genes. Red: narKGHJl operon and grey: genes encoding the molybdopterin moeB, moaE, molB, molA, moeY, moaC, moeA and moaA 
biotyping of C. pseudotuberculosis follows the new trends on clinical microbiology laboratory that is currently incorporating more molecular biology tools in its routine $[23,48]$. In addition, despite not having been tested in the present study, due to its analytical sensitivity of 100 bacteria. It is likely that this quadruplex PCR can also be applied to direct testing from clinical samples, as it has been done successfully for the three-primer ( $16 S$ rRNA, rpoB, and pld) multiplex PCR [14].

The quadruplex PCR proposed in this study facilitates and deepens the level of identification of C. pseudotuberculosis strains at clinical microbiology laboratory, and thereby improves the diagnosis of infection by providing more information for decision making. These results are especially significant considering that C. pseudotuberculosis infects a wide range of hosts and produce different clinical manifestations. Furthermore, it was recently suggested that C. pseudotuberculosis biovars have differences at the molecular phylogenetic level, indicating an anagenesis process within the species $[37,49]$. The evolutionary analysis of conserved genes (rpoB, gapA, fusA, and $r s m E$ ) suggesting a gradual anagenesis of $C$. pseudotuberculosis in that study [49] substantially increases the importance of a molecular technique capable of efficiently separating the biovars Ovis and Equi. In fact, a pan-genome analysis of fifteen C. pseudotuberculosis strains showed a significant number of genes not shared by both biovars, including remarkable differences in the 16 detected pathogenicity islands [50].

In this study, it was also observed that some C. pseudotuberculosis strains (1/06-A, 316, 162 and CIP52.97) were able to reduce nitrate when tested by the biochemical approach and were also positive in the quadruplex PCR assay, albeit did not show in their genomes genes associated with nitrate reduction. The genomic analysis of nitrate locus identified that partial genes encoding the molybdopterin and narKGHJI operon of these strains was absent [21]. These results may have been due to low overall coverage, poor capture efficiency of certain regions, genomic regions that were previously not assembled or poorly assembled, including unambiguously aligning repetitive regions, such as transposons, and difficulty in unambiguously aligning repetitive regions $[41,51]$. Then, after resequencing of the narKGHJI operon region and optical mapping of these strains, it was observed that these strains have the nitrate locus in their genome and corrections on their information on GenBank are under way.

\section{Conclusions}

A novel quadruplex PCR assay for C. pseudotuberculosis species and biovar identification was developed. The nitrate reductase gene narG was included in the assay along with the $16 \mathrm{~S}, \mathrm{rpoB}$ and pld genes to improve the diagnosis of the multiplex PCR at biovar level. There was a significant concordance between the biovar classification provided by the molecular and biochemical test. The ability of the expanded quadruplex PCR assay to discriminate between C. pseudotuberculosis biovar Ovis and Equi strains enhances its value.

\section{Additional file}

Additional file 1: Figure S1. A and B) 1\% agarose gel containing the result of PCR performed for molecular confirmation of the amplicom narKGHJ operon and narT gene of C31, 258, 162, 5297 and 106/A strains. (DOCX $116 \mathrm{~kb}$ )

\section{Abbreviations}

CLA: Caseous Lymphadenitis; Mo-bisMGD: Molybdopterin-guanine-dinucleotide; NAR: Nitrate Reductase; OSD: Oedematous Skin Disease

\section{Acknowledgements}

This study was supported by the Conselho Nacional de Desenvolvimento Científico e Tecnológico (CNPq) and the Fundação de Amparo à Pesquisa do Estado de Minas Gerais (Fapemig). APL and VA thanks CNPq for their fellowships. APL is also indebted to Programa Pesquisador Mineiro (PPM 00923-15) - Fapemig.

\section{Funding}

APL was supported by the Programa Pesquisador Mineiro - PPM (00923-15) from Fapemig and SA was supported by the Universal (481,792/2013-9) from Conselho Nacional de Desenvolvimento Científico e Tecnológico (CNPq).

\section{Availability of data and materials}

The information supporting the conclusions of this article is included in the article.

\section{Authors' contributions}

SA: drafted and wrote the manuscript, and analyzed the data. ED: drafted the manuscript and performed biochemistry tests. CD: performed biochemistry tests. VACA: development of scripts and computational analysis. CS, JA and PB performed laboratory experiments. VA, DB and AL: wrote the manuscript. VA, AC, SS, AL and HF: contributed to conception and design. All authors read and approved the final manuscript.

Ethics approval and consent to participate

Not applicable.

\section{Competing interests}

The authors declare that they have no competing interests.

\section{Publisher's Note}

Springer Nature remains neutral with regard to jurisdictional claims in published maps and institutional affiliations.

\section{Author details}

${ }^{1}$ Instituto de Ciências Biológicas, Federal University of Minas Gerais, Belo Horizonte, MG, Brazil. ${ }^{2}$ Escola de Veterinária, Federal University of Minas Gerais, Belo Horizonte, MG, Brazil. ${ }^{3}$ Departamento de Medicina Veterinária, Federal University of Lavras, Lavras, MG, Brazil. ${ }^{4}$ Centro de Energia Nuclear na Agricultura, University of Sao Paulo, Piracicaba, SP, Brazil. ${ }^{5}$ Instituto de Ciências Biológicas, Federal University of Para, Belém, PA, Brazil. ${ }^{6}$ Department of Medicine and Epidemiology, UC Davis School of Veterinary Medicine, Davis, CA, USA. ${ }^{7}$ Centre for Genomics and Applied Gene Technology, Institute of Integrative Omics and Applied Biotechnology (IIOAB), Nonakuri, Purba Medinipur, WB, India. ${ }^{8}$ Aquacen - National Reference Laboratory for Aquatic Animal Diseases, Federal University of Minas Gerais, Belo Horizonte, $M G$, Brazil. 
Received: 5 July 2016 Accepted: 14 September 2017 Published online: 25 September 2017

\section{References}

1. Shpigel NY, Elad D, Yeruham I, Winkler M, Saran A. An outbreak of Corynebacterium pseudotuberculosis infection in an Israeli dairy herd. Vet. Rec. 1993;133:89-94.

2. Peel MM, Palmer GG, Stacpoole AM, Kerr TG. Human lymphadenitis due to Corynebacterium pseudotuberculosis: report of ten cases from Australia and review. Clin. Infect. Dis. Off. Publ. Infect. Dis. Soc. Am. 1997;24:185-91.

3. Lopes T, Silva A, Thiago R, Carneiro A, Dorella FA, Rocha FS, et al. Complete genome sequence of Corynebacterium pseudotuberculosis strain Cp267, isolated from a llama. J Bacteriol. 2012;194:3567-8.

4. Tejedor-Junco MT, Lupiola P, Schulz U, Gutierrez C. Isolation of nitratereductase positive Corynebacterium pseudotuberculosis from dromedary camels. Trop Anim Health Prod. 2008;40:165-7.

5. Biberstein EL, Knight HD, Jang S. Two biotypes of Corynebacterium pseudotuberculosis. Vet. Rec. 1971;89:691-2.

6. Selim SA. Oedematous skin disease of buffalo in Egypt. J. Vet. Med. B infect. Dis. Vet. Public Health. 2001:48:241-58.

7. Pratt SM, Spier SJ, Carroll SP, Vaughan B, Whitcomb MB, Wilson WD. Evaluation of clinical characteristics, diagnostic test results, and outcome in horses with internal infection caused by Corynebacterium pseudotuberculosis: 30 cases (1995-2003). J Am Vet Med Assoc. 2005;227:441-8

8. Baird GJ, Fontaine MC. Corynebacterium pseudotuberculosis and its role in ovine caseous lymphadenitis. J Comp Pathol. 2007;137:179-210.

9. Guimarães, Alessandro de Sá, Carmo, Filipe Borges, Pauletti, Rebeca Barbosa, Seyffert, Núbia, Ribeiro, Dayana, Lage, Andrey Pereira, et al. Caseous lymphadenitis: epidemiology, diagnosis, and control. $\| O A B$ J. 2011;2:33-43.

10. Shigidi MT. A comparison of five serological tests for the diagnosis of experimental Corynebacterium Ovis infection in sheep. Br Vet J. 1979;135:172-7

11. Brown CC, Olander HJ, Alves SF. Synergistic hemolysis-inhibition titers associated with caseous lymphadenitis in a slaughterhouse survey of goats and sheep in northeastern Brazil. Can. J. Vet. Res. Rev. Can. Rech. Vét. 1987;51:46-9.

12. Menzies PI, Muckle CA. The use of a microagglutination assay for the detection of antibodies to Corynebacterium pseudotuberculosis in naturally infected sheep and goat flocks. Can J Vet Res Rev Can Rech Vét. 1989:53:313-8.

13. Dercksen DP, Brinkhof JM, Dekker-Nooren T, Maanen K, Bode CF, Baird G, et al. A comparison of four serological tests for the diagnosis of caseous lymphadenitis in sheep and goats. Vet Microbiol. 2000;75:167-75.

14. Pacheco LGC, Pena RR, Castro TLP, Dorella FA, Bahia RC, Carminati R, et al. Multiplex PCR assay for identification of Corynebacterium pseudotuberculosis from pure cultures and for rapid detection of this pathogen in clinical samples. J Med Microbiol. 2007;56:480-6.

15. Williams RA, Sadler SA. Electrophoresis of glucose-6-phosphate dehydrogenase, cell wall composition and the taxonomy of heterofermentative lactobacilli. J Gen Microbiol. 1971:65:351-8.

16. Sankarasubramanian J, Vishnu US, Gunasekaran P, Rajendhran J. A genome-wide SNP-based phylogenetic analysis distinguishes different biovars of Brucella suis. Infect Genet Evol. 2016;41:213-7.

17. Yeruham I, Braverman Y, Shpigel NY, Chizov-Ginzburg A, Saran A, Winkler M. Mastitis in dairy cattle caused by Corynebacterium pseudotuberculosis and the feasibility of transmission by houseflies. I Vet Q. 1996;18:87-9.

18. Yeruham I, Elad D, Van-Ham M, Shpigel NY, Perl S. Corynebacterium pseudotuberculosis infection in Israeli cattle: clinical and epidemiological studies. Vet. Rec. 1997;140:423-7.

19. Steinman A, Elad D, Shpigel NY. Ulcerative lymphangitis and coronet lesions in an Israeli dairy herd infected with Corynebacterium pseudotuberculosis. Vet. Rec. 1999;145:604-6.

20. Yeruham I, Elad D, Perl S, Ram A. Necrotic-ulcerative dermatitis on the heels of heifers in a dairy herd infected with Corynebacterium pseudotuberculosis. Vet Rec. 2003;152:598-600.

21. Almeida S, Sousa C, Abreu V, Diniz C, Dorneles EMS, Lage AP, et al. Exploration of nitrate Reductase metabolic pathway in Corynebacterium pseudotuberculosis. Int J Genomics. 2017;2017:1-12.
22. Gonçalves JL, Tomazi T, Barreiro JR, Braga PA, Ferreira CR, Araújo Junior JP, et al. Identification of Corynebacterium spp. isolated from bovine intramammary infections by matrix-assisted laser desorption ionization-time of flight mass spectrometry. Vet Microbiol. 2014;173:147-151.

23. Raoult D, Fournier PE, Drancourt M. What does the future hold for clinical microbiology? Nat. Rev. Microbiol. 2004;2:151-9.

24. Langoni H, Camargo da Silva CP, Troncarelli MZ, Tata A, Belaz KRA, Eberlin $\mathrm{MN}$, et al. Short communication: identification of Corynebacterium Bovis by matrix-assisted laser desorption/ionization mass spectrometry. J Dairy Sci. [Internet]. 2017 [cited 2017 Apr 1]; Available from: http://linkinghub.elsevier. com/retrieve/pii/S0022030217302539

25. Ade Guimarães S, EMS D, Andrade Gl, Lage AP, Miyoshi A, Azevedo V, et al. Molecular characterization of Corynebacterium pseudotuberculosis isolates using ERIC-PCR. Vet Microbiol. 2011;153:299-306.

26. Dorneles EMS, Santana JA, Ribeiro D, Dorella FA, Guimarães AS, Moawad MS, et al. Evaluation of ERIC-PCR as genotyping method for Corynebacterium pseudotuberculosis isolates. PLoS One. 2014;9:e98758.

27. Dorneles EMS, Santana JA, Andrade Gl, Santos ELS, Guimarães AS, Mota RA, et al. Molecular characterization of Corynebacterium pseudotuberculosis isolated from goats using ERIC-PCR. Genet Mol Res GMR. 2012;11:2051-9.

28. MacFaddin JF. Biochemical tests for identification of medical bacteria. 3rd ed. Philadelphia: Lippincott Williams \& Wilkins; 2000.

29. Coyle MB, Lipsky BA. Coryneform bacteria in infectious diseases: clinical and laboratory aspects. Clin Microbiol Rev. 1990;3:227-46.

30. Pitcher DG, Saunders NA, Owen RJ. Rapid extraction of bacterial genomic DNA with guanidium thiocyanate. Lett Appl Microbiol. 1989;8:151-6.

31. Cetinkaya B, Karahan M, Atil E, Kalin R, De Baere T, Vaneechoutte M. Identification of Corynebacterium pseudotuberculosis isolates from sheep and goats by PCR. Vet Microbiol. 2002;88:75-83.

32. Khamis A, Raoult D, La Scola B. rpoB gene sequencing for identification of Corynebacterium species. J Clin Microbiol. 2004;42:3925-31.

33. Revelle, W. psych: Procedures for Psychological, Psychometric, and Personality Research [Internet]. Northwestern University, Evanston, Illinois, USA.; 2015. Available from: https://cran.r-project.org/web/packages/psych/index.html

34. Rotondi, M. A. epibasix: Elementary Epidemiological Functions for Epidemiology and Biostatistics [Internet]. 2012. Available from: https://cran.rproject.org/web/packages/epibasix/index.html.

35. R Development Core Team. R: A Language and Environment for Statistical Computing. Vienna, Austria : the R Foundation for Statistical Computing; 2011.

36. Clegg S, Yu F, Griffiths L, Cole JA. The roles of the polytopic membrane proteins NarK, NarU and NirC in Escherichia Coli K-12: two nitrate and three nitrite transporters. Mol Microbiol. 2002;44:143-55.

37. Cohen J. A coefficient of agreement for nominal scales. Educ Psychol Meas. 1960:20:37-46.

38. Asfour HAE, Darwish SF. Evaluation of phenotypic methods versus molecular methods for differentiation of Coagulase positive staphylococci causing bovine mastitis with a special reference to atypical Staphylococcus Aureus. Int J Curr Microbiol Appl Sci. 2014;3(5):543-58.

39. Campbell EA, Pavlova O, Zenkin N, Leon F, Irschik H, Jansen $R$, et al. Structural, functional, and genetic analysis of sorangicin inhibition of bacterial RNA polymerase. EMBO J. 2005;24:674-82.

40. Gagneux S, Long CD, Small PM, Van T, Schoolnik GK, Bohannan BJM. The competitive cost of antibiotic resistance in mycobacterium tuberculosis. Science. 2006;312:1944-6.

41. Ocheretina O, Escuyer VE, Mabou M-M, Royal-Mardi G, Collins S, Vilbrun SC, et al. Correlation between Genotypic and Phenotypic Testing for Resistance to Rifampin in Mycobacterium tuberculosis Clinical Isolates in Haiti: Investigation of Cases with Discrepant Susceptibility Results. Mokrousov I, editor. PLOS ONE. 2014;9:e90569.

42. Yang B. Relationship between antimycobacterial activities of rifampicin, rifabutin and KRM-1648 and rpoB mutations of mycobacterium tuberculosis. J Antimicrob Chemother. 1998:42:621-8.

43. Boehme CC, Nicol MP, Nabeta P, Michael JS, Gotuzzo E, Tahirli R, et al. Feasibility, diagnostic accuracy, and effectiveness of decentralised use of the Xpert MTB/RIF test for diagnosis of tuberculosis and multidrug resistance: a multicentre implementation study. Lancet. 2011;377:1495-505.

44. Yang H, Qin L, Wang Y, Zhang B, Liu Z, Ma H, et al. Detection of mycobacterium tuberculosis based on H37Rv binding peptides using surface functionalized magnetic microspheres coupled with quantum dots - a nano detection method for mycobacterium tuberculosis. Int J Nanomedicine. 2015;10:77-88. 
45. Songer JG, Beckenbach K, Marshall MM, Olson GB, Kelley L. Biochemical and genetic characterization of Corynebacterium pseudotuberculosis. Am J Vet Res. 1988:49:223-6.

46. Sutherland SS, Hart RA, Buller NB. Genetic differences between nitratenegative and nitrate-positive C. Pseudotuberculosis strains using restriction fragment length polymorphisms. Vet. Microbiol. 1996;49:1-9.

47. Tan MP, Sequeira P, Lin WW, Phong WY, Cliff P, Ng SH, et al. Nitrate Respiration Protects Hypoxic Mycobacterium tuberculosis Against Acidand Reactive Nitrogen Species Stresses. Neyrolles O, editor. PLoS ONE. 2010;5:e13356.

48. Fournier P-E, Drancourt M, Colson P, Rolain J-M, Scola BL, Raoult D. Modern clinical microbiology: new challenges and solutions. Nat Rev Microbiol. 2013;11:574-85.

49. Oliveira A, Teixeira P, Azevedo M, Jamal SB, Tiwari S, Almeida S, et al. Corynebacterium pseudotuberculosis may be under anagenesis and biovar Equi forms biovar Ovis: a phylogenic inference from sequence and structural analysis. BMC Microbiol. 2016:16:100

50. Soares SC, Trost E, Ramos RTJ, Carneiro AR, Santos AR, Pinto AC, et al. Genome sequence of Corynebacterium pseudotuberculosis biovar equi strain 258 and prediction of antigenic targets to improve biotechnological vaccine production. J Biotechnol. 2013;167:135-41.

51. Faino L, Seidl MF, Datema E, van den Berg GCM, Janssen A, AHJ W, et al Single-molecule real-time sequencing combined with optical mapping yields completely finished fungal genome. MBio. 2015;6:e00936-15.

\section{Submit your next manuscript to BioMed Central} and we will help you at every step:

- We accept pre-submission inquiries

- Our selector tool helps you to find the most relevant journal

- We provide round the clock customer support

- Convenient online submission

- Thorough peer review

- Inclusion in PubMed and all major indexing services

- Maximum visibility for your research

Submit your manuscript at www.biomedcentral.com/submit 